University of Northern lowa

UNI ScholarWorks

1998

\title{
Cluster Grouping Elementary Gifted Students in the Regular Classroom: A Teacher's Perspective
}

\author{
Kevin Michael Teno \\ University of Northern lowa
}

Let us know how access to this document benefits you

Copyright (C1998 Kevin Michael Teno

Follow this and additional works at: https://scholarworks.uni.edu/grp

Part of the Curriculum and Instruction Commons

\section{Recommended Citation}

Teno, Kevin Michael, "Cluster Grouping Elementary Gifted Students in the Regular Classroom: A Teacher's Perspective" (1998). Graduate Research Papers. 1861.

https://scholarworks.uni.edu/grp/1861

This Open Access Graduate Research Paper is brought to you for free and open access by the Student Work at UNI ScholarWorks. It has been accepted for inclusion in Graduate Research Papers by an authorized administrator of UNI ScholarWorks. For more information, please contact scholarworks@uni.edu. 


\title{
Cluster Grouping Elementary Gifted Students in the Regular Classroom: A Teacher's Perspective
}

\begin{abstract}
Cluster grouping is a programming option that is receiving increased attention as a method of serving gifted students in regular heterogeneously grouped classrooms. This article provides an overview of the literature on cluster grouping and also examines the advantages and disadvantages of clustering from the perspective of conclusions obtained through actual implementation in an elementary school district. The conclusions indicate that clustering, if carefully planned and implemented, provides a viable option in meeting the needs of gifted students and improves the education of all students in the regular classroom.
\end{abstract}


Cluster Grouping Elementary Gifted Students in the Regular Classroom:

A Teacher's Perspective

\author{
A Publishable Article \\ Submitted to the \\ Department of Curriculum and Instruction \\ in Partial Fulfillment \\ of the Requirements for the Degree \\ Master of Arts in Education
}

University of Northern Iowa

by

Kevin Michael Teno

December 1998 
This Publishable Article by: Kevin Michael Teno

Entitled: $\quad$ CLUSTER GROUPING ELEMENTARY GIFTED STUDENTS IN THE REGULAR CLASSROOM: A TEACHER'S PERSPECTIVE

Has been approved as meeting the research requirements for the Degree of Master of Arts in Education.

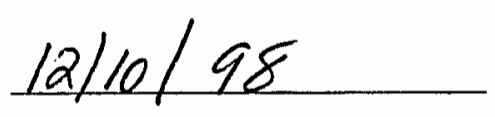

Date Approved

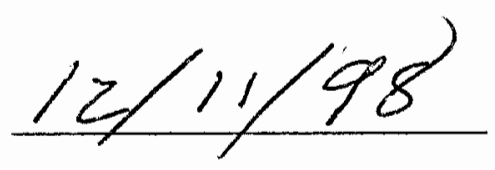

Date Approved

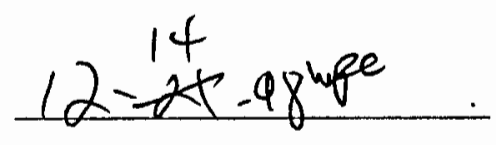

Date Approved

\section{William Waack}

Graduate Faculty Reader

Charles R. May

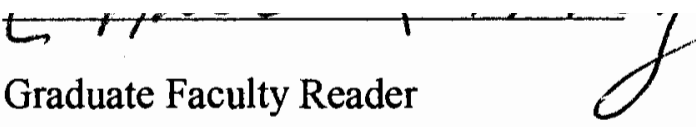

W. P. Callahan

Head, Department of Curriculum and Instruction 


\section{Abstract}

Cluster grouping is a programming option that is receiving increased attention as a method of serving gifted students in regular heterogeneously grouped classrooms. This article provides an overview of the literature on cluster grouping and also examines the advantages and disadvantages of clustering from the perspective of conclusions obtained through actual implementation in an elementary school district. The conclusions indicate that clustering, if carefully planned and implemented, provides a viable option in meeting the needs of gifted students and improves the education of all students in the regular classroom. 
1306 North Seventh Street

Indianola, Iowa 50125

December, 1998

Ms. Ruthan Brodsky, Editor

Roeper Review

PO Box 329

Bloomfield Hills, MI 48303

Dear Ms. Brodsky:

I would appreciate your consideration of the enclosed manuscript for publication. I have written "Cluster Grouping Elementary Gifted Students in the Regular Classroom: A Teacher's Perspective" in partial fulfillment of the requirements for a Master of Arts in Education of the Gifted from the University of Northern Iowa. I am currently a gifted education specialist at Saydel Community School District in Des Moines, lowa. I received my Bachelors of Arts in Education from Simpson College.

The accompanying article was written to examine the advantages and disadvantages of cluster grouping from the perspective of conclusions abtained through actual implementation in an elementary school district. The manuscript is 19 pages long including the title page, abstract, text and references. Throughout the manuscript, I have followed the guidelines established in the Publication Manual of the American Psychological Association, Fourth Edition.

If you have any questions or concerns regarding this manuscript, you may contact me at the address above, by telephone (515-961-3120), or by E-mail (tenok@saydel.k12.ia.us).

Thank you for your attention to this manuscript.

Sincerely,

Kewin Michael Tes:o

Kevin Michael Teno

encl. 
Cluster grouping is an administrative procedure in which all gifted students at a grade level are assigned to one classroom because of similar learning needs. Typically, these students are assigned to a general education teacher who has an interest or has specific training in how to instruct gifted students. The other students assigned in the classroom are of mixed ability.

According to Hoover, Sayler, and Feldhusen (1993), the major purpose of cluster grouping is to allow identified gifted students to receive all of their instruction within the regular classroom. Such a strategy is considered to be less disruptive than when students are "pulled out" to receive services. Hoover, Sayler, and Feldhusen (1993) also noted that cluster grouping allows students to receive instruction from one teacher rather than from several teachers who infrequently collaborate with each other about student progress.

With the current trend in education to provide the inclusion of all students within the general education classroom, there is an initiative to provide for greater collaboration between gifted education specialists and classroom teachers as a method for improving education for all students. Since gifted students, for the most part, spend the majority of their school day in the general education classroom, it is only practical that the teacher's delivery of services includes a systemic strategy that assists with meeting the specific needs of these children in that learning environment. The gifted education specialist's role in such learning environments is to serve as a resource for classroom teachers, as well as to assist with modifications in the general education classroom. There is a concern, however, when we look at what a general education teacher is asked to do on a daily basis: They are required not only to make modifications for special education 
students, but also to provide appropriate curricular options for gifted students (Coleman, 1995).

It is not surprising, therefore, that the strategy of clustering is increasingly identified as one proposed solution to lessen the burden on general education teachers and to address the needs of gifted students (Parpart, 1995). Winebrenner (1992) emphasized that all children have a right to learn every day in class and that it is the strategy of cluster grouping that provides "the same opportunities for the gifted that all other kids' experiences: consistent opportunities for learning challenges" (p. 127). It is this challenge that educational programs must address in providing differentiated services for gifted students within the general education classroom.

This article will examine cluster grouping as a viable option for meeting the needs of gifted and talented students. It will also examine the strengths and weaknesses of cluster grouping from the perspective of conclusions obtained through actual implementation of this strategy in an elementary school district.

\section{Cluster Grouping as a Viable Option}

According to the literature, cluster grouping can be successful in meeting the needs of gifted students in the regular classroom. Several researchers in the field of gifted education have identified several positive aspects of establishing cluster groups which makes it a viable option.

One advantage of cluster grouping for gifted students is that it provides an opportunity to be grouped with intellectual peers. Hoover, Sayler, and Feldhusen (1993) concluded that gifted students should have the opportunity to interact with like ability 
peers for intellectual, social and emotional support. According to Winebrenner and Devlin (1996), cluster grouping allows gifted students to feel less isolated and less stressed because they are clustered with other students of similar abilities. Winebrenner (1992) also noted that cluster grouping provides gifted students with the opportunity to select more challenging activities and produce more in-depth and quality products because they are working with others within the classroom environment instead of working alone.

There are advantages for the regular students as well. Gentry (1996) stated: "The implications are that when a cluster grouping model is implemented, there may be a positive effect on the achievement and identification of all students, not just those identified and placed in the cluster for high ability students" (p.11). She also concluded that cluster grouping allows the highest achieving students to be removed from other classrooms, thereby allowing new leaders to emerge. Hoover, Sayler, \& Feldhusen (1993) noted that high ability students who are not formally identified could be included with the cluster group for opportunities in their area of strength.

According to some researchers, the use of cluster grouping also offers a financial advantage to school districts. Parpart (1995) reported that cluster grouping requires little additional money to support while providing a full-time gifted program. School districts can financially provide their students with the daily educational experiences that they need (Parpart, 1995). Winebrenner (1992) pointed out that, with the exception of teacher training, no additional funds are needed for its implementation. She stated: "Cluster grouping provides gifted students with something their parents have always been told the district could never afford: a full-time gifted program" (p. 129). 
In summary, "the structure that provides optimum grouping practices for all students is cluster grouping" (Winebrenner, 1992, p. 125). For the gifted students, the advantages are that they feel more comfortable when they are with other students of comparable abilities. They are also more likely to select challenging activities when they work with other gifted students. The advantages for regular students are that they can be included with the cluster group for activities that are appropriate for their areas of strength. New academic leaders can also emerge at those times when gifted students are not present in the classroom. In addition, the advantage for the school is that cluster grouping is a cost-effective strategy for meeting the needs of gifted students on a daily basis.

\section{Negative Aspects of Cluster Grouping}

While the literature indicates that cluster grouping is effective, it also points to some limitations that ought to be addressed before successfully implementing this strategy. One such limitation is the criticism that cluster grouping is another word for tracking. Winebrenner (1992) concluded that cluster grouping and tracking are different: In a tracking system, all students are grouped by ability for much of the school day, and students tend to remain in the same track throughout their years in school. In cluster grouping, only the gifted are grouped together in their areas of strength, because they learn better that way. Students of all other ability levels are grouped heterogeneously, because present research indicates that this is the best arrangement for them (p. 126). 
According to Kulik and Kulik (1991), gifted students learn better when they are cluster grouped according to their areas of strength. Winebrenner and Devlin (1996) concluded that cluster grouping allows gifted students to learn together, while avoiding permanent placement for all other students.

An added problem that may detract from the effectiveness of cluster grouping is the selection and training of cluster teachers. Parpart (1995) concluded that the teacher who is responsible for the instruction of the cluster group should have a desire and be qualified to teach them. She also noted that if students are clustered but instructional strategies are not changed, then cluster grouping could be a disservice to students. According to Hoover, Sayler, \& Feldhusen (1993), teachers need training in working with gifted students and curriculum differentiation. Winebrenner and Devlin (1996) determined that the success of the cluster grouping strategy depends on how well the general education classroom teachers are trained in curriculum compacting, accelerating the pace of instruction, providing enrichment, and incorporating students' interests into their independent study projects. It is important to cluster group gifted students with a teacher who has a specific background in gifted education and who has the skills necessary to differentiate curriculum.

Beyond having trained teachers, Hoover, Sayler, \& Feldhusen (1993) determined that another barrier in the successful implementation of cluster grouping is the amount of work required of general education classroom teachers. Schuler (1997) noted that with the increased responsibility of the cluster group, teachers revealed that their workload increased and that they did not have enough collaboration time. Rogers (1991) indicated teachers need to be given adequate time to plan and provide appropriate instruction for 
the cluster group. Coleman (1992) concluded that the cluster teacher should consult with the gifted education specialist who has training in meeting the needs of gifted students. Furthermore, Coleman (1992) stated: "This specialist should help plan curriculum compacting, select and procure appropriate materials, team teach lessons, and facilitate independent student projects" (p. 39).

In summary, the literature has indicated that there are some limitations of cluster grouping that should be examined before implementing this strategy. One limitation is that clustering is another word for tracking. Another limitation is that cluster teachers need proper training. A final limitation of cluster grouping is that the cluster teacher's workload increases.

The responsibilities placed on general education teachers are tremendous. In addition, the needs of the students who come to school each day reflect a diversity of backgrounds which offers a challenge to educators. Teachers must continually work to address the needs of all students, including the gifted. As these students present challenges, there is a need to provide alternative ways of serving gifted students. The next section of this article examines cluster grouping as one possible solution to meeting the needs of gifted students within one general education classroom.

\section{A Pilot Study}

As a gifted education specialist in a suburban elementary school district, the issue of cluster grouping became increasingly important to me in my teaching assignment. Since my professional responsibilities included more than one elementary building and since the gifted students were scattered among several general education classrooms, I 
developed some concerns related to the effectiveness of educational services to gifted students. One of my concerns was that there was a lack of communication between the general education teachers and me. Another concern was the strong indication that general education teachers needed assistance and preparation in modifying the curriculum to meet the needs of gifted students. From my point of view, these concerns made it a necessity to explore alternative methods of delivering services to gifted students, including the option of cluster grouping. I therefore planned, implemented and evaluated a cluster grouping pilot program to examine the extent to which cluster grouping could be used as an option for gifted students and to determine how general education teachers respond to it.

\section{Demographics}

The school system in which I am employed is located in a suburban area in Central Iowa where there are two elementary buildings serving approximately 608 students in grades kindergarten through grade four. The children involved in the experimental cluster group used as a basis for this paper were identified gifted children who were placed in one heterogeneous fourth grade classroom.

The total fourth grade population was comprised of 116 fourth grade students divided among five sections, seven of whom were identified as gifted. Four of the students were identified in reading, two were identified in mathematics, and one was identified as having general intellectual aptitude. The general education classroom teacher and the gifted education specialist were responsible for making content modifications for the identified students. 
The seven gifted and talented students were identified for the gifted cluster prior to entry into the fourth grade based on the following criteria: teacher nominations, behavioral observations, student portfolios, and the Iowa Test of Basic Skills (cut off scores of $90 \%$ or above in one or more of the following areas: vocabulary, reading, language, mathematics concepts, mathematics problems, mathematics total, and core composite).

The students were identified for the gifted and talented program in the areas of general intellectual ability and specific academic aptitude. General intellectual ability refers to students who can learn at a faster pace, master higher levels of content, and handle abstract concepts at a significantly higher level than expected, given the student's chronological age and experience. Specific academic aptitude refers to those students who have exceptionally high achievement or potential and high degree of interest in a specific field of study.

\section{The Program Environment}

The elementary gifted program for this school district is comprised of five service levels. These service levels assist parents and teachers in designing an individually differentiated program based on the strengths and talents of each student.

At the first level, Advocacy, the gifted education specialist aids identified students in individualizing their individual programs, thus enabling students to reach their academic potential. Both cognitive and effective needs are addressed in this level. Components of advocacy include: (a) conducting individual interviews and assessments to diagnose student needs and learning styles; (b) writing and staff detailed PEP 
(Personalized Education Plan) for every identified student with parent, student, and staffing input; (c) implementing and monitoring the Personalized Education Plan; (d) communicating with parents, students, staff, and community on inservicing, programming, planning, and progress; and (e) representing the student's best interest problem solving and advocating for appropriate educational programming.

The second level is Special Opportunities. At this level, special events and opportunities are offered to gifted and talented students and other highly interested, able students. Special opportunities at the elementary level may include activities such as Math Olympiads, National Language Arts Olympiad, Stock Market Game, News Bowl USA, and other activities based on students' needs and interests.

The third service level is Extension of the Regular Curriculum. At this service level, the general education teacher and the gifted education specialist work together to provide opportunities for talent development and enrichment through the regular classroom to benefit all students. Team teaching, extended learning contracts, and/or resourcing are used in this level.

The fourth service level is Modification of the Regular Curriculum. At this level, the gifted education specialist and the general education teacher, along with parents, collaborate to create a plan of instruction and implementation as designed on the PEP. Modifications may include compacting, acceleration, and/or enrichment.

The fifth service level offers a Pull-in class. In this class, the gifted students are removed from the general education classroom and meet with the gifted education specialist for special instruction to work on projects in the areas of academic and general intellectual abilities. Pull-in students are included in this plan because students benefit 
both from individualized instruction and from interaction with like ability peers. The gifted education specialist works with these students on developing process skills which will directly lead to self-directed learning and independent study.

\section{Organizational Structure}

The ideal delivery option for a cluster group would be for the identified gifted students to receive all of their instruction within the general education classroom. Since my teaching assignment includes two elementary buildings with five grade levels, the ideal cluster grouping set-up was not feasible. Therefore, I was assigned to the elementary building that contained the identified cluster group for three days a week. The remaining two days of the week were spent in the other elementary school building.

In order to ensure greater continuity between the regular education program and the gifted program, the cluster teacher and I met once each week for a minimum of thirty minutes. During this time, we had the opportunity to select materials, gather resources, and also plan differentiated activities for the week. The planning time together was also a perfect opportunity for monitoring the progress of the gifted students.

Because the identified students were cluster grouped, I had the opportunity to work with these students for two days a week in both the areas of integrated language arts and math. Depending upon the activities planned for the week, I was able to work with the cluster group either in the general education classroom, or I was able to work with the cluster group in the gifted education classroom. The cluster teacher provided differentiated services to the cluster group during the remaining three days of the week. 
There was a variety of modified activities conducted with the cluster group. Modifications for the identified students in the area of integrated language arts included higher level trade books, higher order thinking skills, and creative writing. Differentiated activities for the identified mathematics students included logic, geometry, problem solving and extensions of the regular classroom curriculum.

In addition to working with the identified students for the core subject areas of integrated language arts and math, I met with the cluster group in a pull-in class for approximately 75 minutes per week. The focus of this class was to utilize a variety of models and teaching strategies that were effective for gifted learners. Curriculum elements for the pull-in class included: (a) orientation of students to TAG and program options; (b) independent, self-directed learning skills; (c) group and independent studies in specific content, and (d) quality student products and presentations.

\section{Evaluation of the Program}

At the end of the first year of implementing the cluster grouping program, I used my own reflections; conferences with teachers; observations in the general education cluster classroom, along with observations in the TAG resource room; and a survey of the fourth grade general education classroom teachers to evaluate the use of the cluster grouping strategy. The positive and negative implications of cluster grouping for participating teachers and students follow. 


\section{Positive Implications of Cluster Grouping.}

After one year of implementing the strategy of cluster grouping and on the basis of survey results, I have discovered several benefits to establishing cluster groups in the general education classroom. For the gifted students, there are positive advantages in providing environments where they can work together. For example, the general education teachers indicated in the survey that clustering allows the gifted students to work together in groups for intellectual stimulation and social support. The cluster teacher also revealed in the survey that she provided these students with more challenging activities. In addition, observations made by the gifted education specialist in both the general education classroom and in the gifted resource room revealed that the cluster group demonstrated a new enthusiasm for learning by working at a pace that was more conducive to individual rates of learning.

There also proved to be advantages for the cluster teacher. First of all, the cluster teacher reported in her survey response that cluster grouping allows one general education teacher to design modified activities instead of having several general education teachers each design activities separately for gifted students. The cluster teacher also noted in the survey that clustering allows the general education teacher more individualized time to work with other students in that classroom. Furthermore, she stated in her response that there was an increase in communication and support between the cluster teacher and the gifted education specialist.

Interestingly, cluster grouping also seemed to benefit regular students. The cluster teacher disclosed in the survey that by collaborating with the gifted education specialist, the gifted students were provided with a modified curriculum, exposed to 
higher level questioning strategies and presented with more hands-on learning activities. Significantly, she also indicated that clustering raised the standards and expectations for the whole class. In fact, in some cases, a number of non-identified high ability students also were included in certain activities based upon their interests and abilities.

\section{Negative Implications of Cluster Grouping.}

There were a few pitfalls that hindered the successful implementation of the cluster grouping strategy in this particular pilot. First, the cluster teacher indicated in the survey that, with the increased responsibility of the cluster group, extra time was needed in preparing materials and planning instruction for this group. To help minimize the problem associated with time, she suggested that it is necessary that the cluster teacher be given adequate time to prepare lessons and materials for the cluster group. Furthermore, she stated that sufficient time is needed to collaborate with the gifted and talented specialist in order to assist with providing appropriate services for gifted students.

Second, non-cluster teachers indicated that cluster grouping allowed few, if any chances for each classroom to enjoy gifted students modeling for others. Winebrenner (1992) noted that it is important to ensure other high ability students are included into non-clustered classrooms so they have opportunities to serve as positive role models and also become new leaders in classes that no longer contain the cluster group.

A final concern that was noted by one non-cluster teacher was her belief that cluster grouping tracks students. In order to address this particular criticism, I believe that it is imperative to educate the staff, parents and students as to the research relative to cluster grouping. Winebrenner (1992) is in agreement with this observation. She 
recommended providing staff development for all teachers. She also suggested that rotating the staff every year or two helps to send a message to parents that there are many teachers who can provide appropriate educational opportunities for gifted students.

\section{Conclusions and Recommendations}

My examination of the literature related to cluster grouping as a strategy for meeting the needs of gifted students in the context of the total school environment convinced me of its feasibility. My implementation of the strategy through a pilot study provided a unique opportunity to test that feasibility. These two activities have led me to reach some tentative conclusions concerning the effectiveness of cluster grouping as well as some recommendations for the improvement and expansion of this strategy in the gifted education classroom.

First of all, the reviewed literature reflected a current trend in education that strongly focuses on a desire to improve instruction for all students. Therefore, it seems evident that gifted education programs should interface their services with general education programs in order to implement a schoolwide collaboration process that focuses on school improvement. The strategy of cluster grouping gifted students within the general education classroom and the resultant modification of the curriculum can be one effective component in restructuring schools to improve classroom instruction for all children, including the gifted and talented.

Second, the reviewed literature showed that collaboration and proper planning increases the likelihood of success in cluster grouping. Collaboration of the cluster teacher with the gifted education specialist is important in both the planning and the 
implementation of instructional strategies to meet the needs of these students. Through a collaborative effort, the cluster teacher's methods of teaching are enhanced and gifted students are provided with more comprehensive services, rather than programs limited to relatively infrequent short periods of time when they are "pulled in" to work with the gifted education specialist. My pilot study also reaffirmed that collaboration is an important ingredient in the success of cluster grouping. From my personal observations, collaboration provided the cluster teacher and me the opportunity to benefit from exposure to each other's training and experience while working together as a team to create an environment that provides learning opportunities for all students to become successful learners in the general education classroom.

Third, from the reviewed literature it became apparent that the selection of the cluster teacher is critical to the success of cluster grouping. This professional should have an interest and a desire to work with gifted students rather than having the cluster group assigned by an administrator. The cluster teacher also should be provided with the proper training, resources and support needed to address the characteristics of gifted students who require curriculum modifications that extend beyond that provided in the general education classroom. Too, the cluster teacher must be willing to dedicate a proportionate amount of classroom time to providing appropriate learning opportunities for the cluster group. My pilot study reaffirmed that the selection of the cluster teacher is important to the cluster grouping process. In working with the cluster teacher, I observed that she was willing to devote extra planning time and classroom instructional time to provide appropriate learning opportunities for the cluster group. 
Fourth, the planning, implementation and evaluation of this study have convinced me that the cluster grouping strategy does not need nor should it be designed to replace the current gifted program. The value of this approach lies in its implementation as a supplement to current gifted programs and as a flexible strategy that can be modified to meet the goals and objectives of other districts, including those that have more than one building. My work with teachers, parents, and administrators also led me to conclude that while clustering is successful, it can not stand alone. Teachers are faced with the difficult task of providing differentiated instruction to 25-30 students in a classroom. Therefore, it is imperative that the general education teachers work collaboratively with the gifted education specialist to implement the cluster grouping strategy and make daily modifications in curriculum development in order to meet the needs of our most capable students. In addition, administrators should provide both general education teachers and cluster teachers with on-going staff development on the strategies designed to meet the unique needs of gifted students. This, in turn, may well benefit other non-identified students.

In conclusion, the results of this pilot support the reviewed research showing that gifted students do benefit from the cluster grouping approach. Indeed, the practice of cluster grouping is a strategy which ensures that gifted students will continue to receive quality educational services while schools work at the same time to improve learning experiences for all students in the general education classroom. 


\section{References}

Coleman, M. R. (1995). The importance of cluster grouping. Gifted Child Today, $18(1), 38-40$.

Gentry, M. (1996, Spring). Total school cluster grouping: An investigation of achievement and identification of elementary school students. The National Research Center on the Gifted and Talented, 8-11.

Hoover, S. M., Sayler, M., \& Feldhusen, J. F. (1993). Cluster grouping of gifted students at the elementary level. Roeper Review, 16 (1), 13-15.

Kulik, J. A., \& Kulik, C. C. (1991). Ability grouping and gifted students. In N. Colangelo \& G. A. Davis (Eds.), Handbook of gifted education (pp. 178-196). Needham Heights, MA: Allyn \& Bacon.

Parpart, M. L. (1995). Cluster grouping students in the regular classroom: Barriers to success. University of Virginia, The Curry School of Education. (ERIC Document Reproduction Service No. ED 384 593).

Rogers, K. B. (1991). Grouping the gifted and talented: Questions and answers. Roeper Review, 16 (1), 8-12.

Schuler, P. A. (1997, Winter). Cluster grouping coast to coast. The National Research Center on the Gifted and Talented, 11-15.

Winebrenner, S. (1992). Teaching gifted kids in the regular classroom. Minneapolis, MN: Free Spirit Publishing Inc.

Winebrenner, S., \& Devlin, B. (1996). Cluster grouping fact sheet: how to provide full-time services for gifted students on reasonable budgets. Brooklyn, MI: Phantom Press. 
Appendix 
The Roeper Review is a quarterly journal of The Roeper School. It draws on all areas of gifted education, including manuscripts with a multidisciplinary focus that pertain to practice, policy, and applied research. Also considered for publication are well thought-out, non. research based reflective manuscripts.

The Roeper Review is a juried publication. Assisted by editorial boards and external reviewers, the editor refers manuscripts deemed suitable to qualified reviewers who have appropriate expertise for recommendation and comment. Reviewers' comments are provided to the author by the Editor. The instructions below should be followed carefully to avoid delay in the review and the publication process.

ORIGINAL ARTICLES ONLY. Submission of a manuscript to this journal represents a certification on the part of tne author(s) that it is an original work, and that reithei this maituscript nor a version of it has been published previously nor is being considered for publication elsewhere. If accepted by this journal, it is not to be published elsewhere without permission from the Roeper Review. Include copies of letters granting permission to reproduce copyrighted materials, if needed.

MANUSCRIPT LENGTH. Your manuscript should be no more than 20 pages double-spaced (including abstract and references). Lengthier manuscripts may be considered at the discretion of the Editor.

MANUSCRIPT STYLE. References, citations, tables, figures, and general style of manuscripts for this journal should follow the APA style las outlined in the fourth edition of the Publication Manua/ of the American Psychological Association). For example, references should be double-spaced and placed in alphabetical order. Consult the style guide for subheadings and tables and figures. No footnotes.

\section{MANUSCRIPT FORMAT}

Margins: Leave at least one-inch margin on all four sides.

Paper: Use white, $8 \mathrm{1} / 2 \times 11$ bond paper.

ilumber of cupies: Four iłij: tne originai pius tinree protocopies.

Cover page: Enclose a cover page but do not attach it to the manuscript. It should contain the article's title, all authors' names, mailing addresses, and telephone/fax numbersie-mail addresses, if available. It also should include one or two sentences about each author and any acknowledgment of support or other credit.

Title page. Staple a title page to the manuscript indicating only the article title for anonymous refereeing.

Abstract: Include an abstract of- no more than- 150 words on a separate page.

Return envelope: Include a 9"X 12" envelope, addressed and stamped with sufficient postage to ensure the return of your manuscript.

TABLES, FIGURES, ILLUSTRATIONS. Place tables on separate pages, double-space. Do not change typeface or font size. Make sure that all figures are properly prepared. These go after the tables and are proceeded by.a separate page containing figure captions. Tables, figures, and illustrations must be cleanly typed or artistically prepared so that they can be used either exactly as they are or else used after a photographic reduction in size. In the the text, skip extra spaces and indicate where tables and figures are to be placed. (Do not write on the art.) Each table should have a title and be numbered consecutively using Arabic numerals.

REFERENCES . Make sure that all citations mentioned in the text are fully referenced in the reference list and that all citations in the reference lit are mentioned in the text. This section begins on a separate page following the end of the ext and is headed References. Make sure all references are complete (with inclusive page numbers) and are formatted according to the style used by this journal.

REVISIONS REQUIRED BY REVIEWERS. Many times a manuscript is accepted by the Editor contingent upon changes that are mandated by anonymous reviewers and members of the editorial boards. If the Editor returns your manuscript/disks for revision, you are responsible for retyping any sections of the paper to incorporate these revisions.

COPYRIGHT. Authors of accepted manuscripts must transfer copyrights to the Roeper Review which holds copyrights to all articles and reviews. However, authors have unlimited rights to republish their articles in volumes that they write or edit and to otherwise duplicate such material for their own use in teaching, lecturing, or similar activity. It is requested that the citation of the volume, number and date of the issue be provided.

ELECTRONIC MEDIA. Upon acceptance, final copies of the manuscript are to be prepared for publication and forwarded to the journal in both hardcopy ( 3 copies) and diskette. On the outside of the diskette write: brand name of computer or word processor, the word processing program used, title of your article and file name. Be specific: include version numbers where applicable and whether your disk has been formatted high-density. We can use IBM-compatible or Mac disks but not Apple. Note: Disk and hard copy must agree. In case of discrepancies it is the policy of this journal to follow the hard copy. Authors are advised that no revisions of the manuscript can be made after acceptance by the editor for publication.

SUBMISSION: Send 4 copies to: Ruthan Brodsky, Editor, Roeper Review, PO Box 329, Bloomfield Hills, MI, 48303. Manuscripts are judged for significance to the field of gifted education, appropriateness of the literature review, clarity of presentation, and adequacy of evidence for conclusions. Research manuscripts are also evaluated for adequacy of the rationale and appropriateness of the design and analysis. Manuscripts that do not meet submission requirements will be returned to the authors. 